\title{
Prognostic Factors for Survival in Pulmonary Hypertension Due to Left Heart Disease
}

\author{
Sayuri Yamabe, MD; Yoshihiro Dohi, MD, PhD; Shinya Fujisaki; Akifumi Higashi, MD; \\ Hiroki Kinoshita, MD; Yoshiharu Sada, MD; Takayuki Hidaka, MD, PhD; Satoshi Kurisu, MD, PhD; \\ Hideya Yamamoto, MD, PhD; Yasuki Kihara, MD, PhD
}

\begin{abstract}
Background: The epidemiological data of pulmonary hypertension (PH) due to left heart disease (LHD) are limited. This study investigated hemodynamic and clinical factors associated with mortality in patients with PH due to LHD.

Methods and Results: We conducted a retrospective review in 243 patients with PH due to LHD, defined as mean pulmonary arterial pressure $\geq 25 \mathrm{mmHg}$ and pulmonary wedge pressure $>15 \mathrm{mmHg}$ at rest in right heart catheterization. Kaplan-Meier and Cox proportional hazard regression analyses were performed. Seventy-five patients died during an average follow-up of 52 months (range, 20-73 months). On multivariate analysis, only diastolic pulmonary vascular pressure gradient (DPG) $\geq 7 \mathrm{mmHg}$ among hemodynamic measurements was a predictor of mortality. Elevated N-terminal pro-brain natriuretic peptide (NT-pro BNP), more severe New York Heart Association (NYHA) class, anemia, and renal dysfunction were more strongly associated with mortality. Mean right atrial pressure (RAP) and currently available markers of pulmonary vascular remodeling including transpulmonary pressure gradient (TPG) and pulmonary vascular resistance (PVR) had no effect on survival.
\end{abstract}

Conclusions: DPG is weakly associated with mortality in PH due to LHD. Clinical factors such as NT-pro BNP, NYHA class, anemia and renal dysfunction are superior predictors. The prognostic ability of hemodynamic factors such as mean RAP, TPG, PVR and DPG is limited. (Circ $J$ 2016; 80: 243-249)

Key Words: Left heart disease; Prognosis; Pulmonary hypertension

$\mathbf{P}$ ulmonary hypertension $(\mathrm{PH})$ due to left heart disease (LHD), classified as group $2 \mathrm{PH}$ according to the latest classification (Nice 2013), has the largest population among 5 groups of $\mathrm{PH}$. PH due to LHD is caused by passive downstream elevation in the left atrial pressure (LAP), or by a combination of pulmonary vasculopathy. ${ }^{1,2}$ Recent epidemiological studies in group $2 \mathrm{PH}$ focused on markers of pulmonary vascular remodeling, such as transpulmonary pressure gradient (TPG), ${ }^{3-6}$ pulmonary vascular resistance (PVR), ${ }^{3,4,6}$ and diastolic pulmonary vascular pressure gradient (DPG). ${ }^{5-8}$ The results obtained so far, however, are controversial. Furthermore, sustained PH leads to right ventricular dysfunction, which is partly represented as elevated mean right atrial pressure (RAP). The prognostic ability of these hemodynamic parameters including mean RAP, TPG, PVR, and DPG in the setting of group $2 \mathrm{PH}$ has not been established. In this retrospective study, we reviewed 243 patients to characterize mortality, and to clarify hemodynamic parameters and clinical characteristics for predicting mortality in patients with $\mathrm{PH}$ due to LHD.

\section{Editorial p 72}

\section{Methods}

The subjects consisted of 243 patients with PH due to LHD enrolled from 1,098 consecutive patients who underwent right heart catheterization (RHC) between February 2000 and May 2013 at Hiroshima University Hospital, Hiroshima, Japan. Volume overload was treated with conventional diuretics prior to the RHC. To diagnose PH due to LHD, mean pulmonary arterial pressure (PAP) $\geq 25 \mathrm{mmHg}$ and pulmonary wedge pressure (PWP) $>15 \mathrm{mmHg}$ at rest were used according to the guideline of the European Society of Cardiology. ${ }^{3}$ The algorithm for patient selection is shown in Figure 1. In this retrospective review, hemodynamic measurements as well as clinical, laboratory, and echocardiographic parameters at the time of RHC were collected from medical records. RHC was performed on the 2nd hospital day (range, 1st-8th hospital day), and echocardiography was performed at the time of

Received June 28, 2015; revised manuscript received September 28, 2015; accepted October 8, 2015; released online November 17, 2015 Time for primary review: 29 days

Department of Cardiovascular Medicine, Hiroshima University Graduate School of Biomedical and Health Sciences, Hiroshima (S.Y., Y.D., A.H., H.K., Y.S., T.H., S.K., H.Y., Y.K.); School of Medicine, Hiroshima University, Hiroshima (S.F.), Japan

Mailing address: Yoshihiro Dohi, MD, PhD, Department of Cardiovascular Medicine, Hiroshima University Graduate School of Biomedical and Health Sciences, 1-2-3 Kasumi, Minami-ku, Hiroshima 734-0037, Japan. E-mail: yuyudohi@ gmail.com

ISSN-1346-9843 doi:10.1253/circj.CJ-15-0708

All rights are reserved to the Japanese Circulation Society. For permissions, please e-mail: cj@j-circ.or.jp 


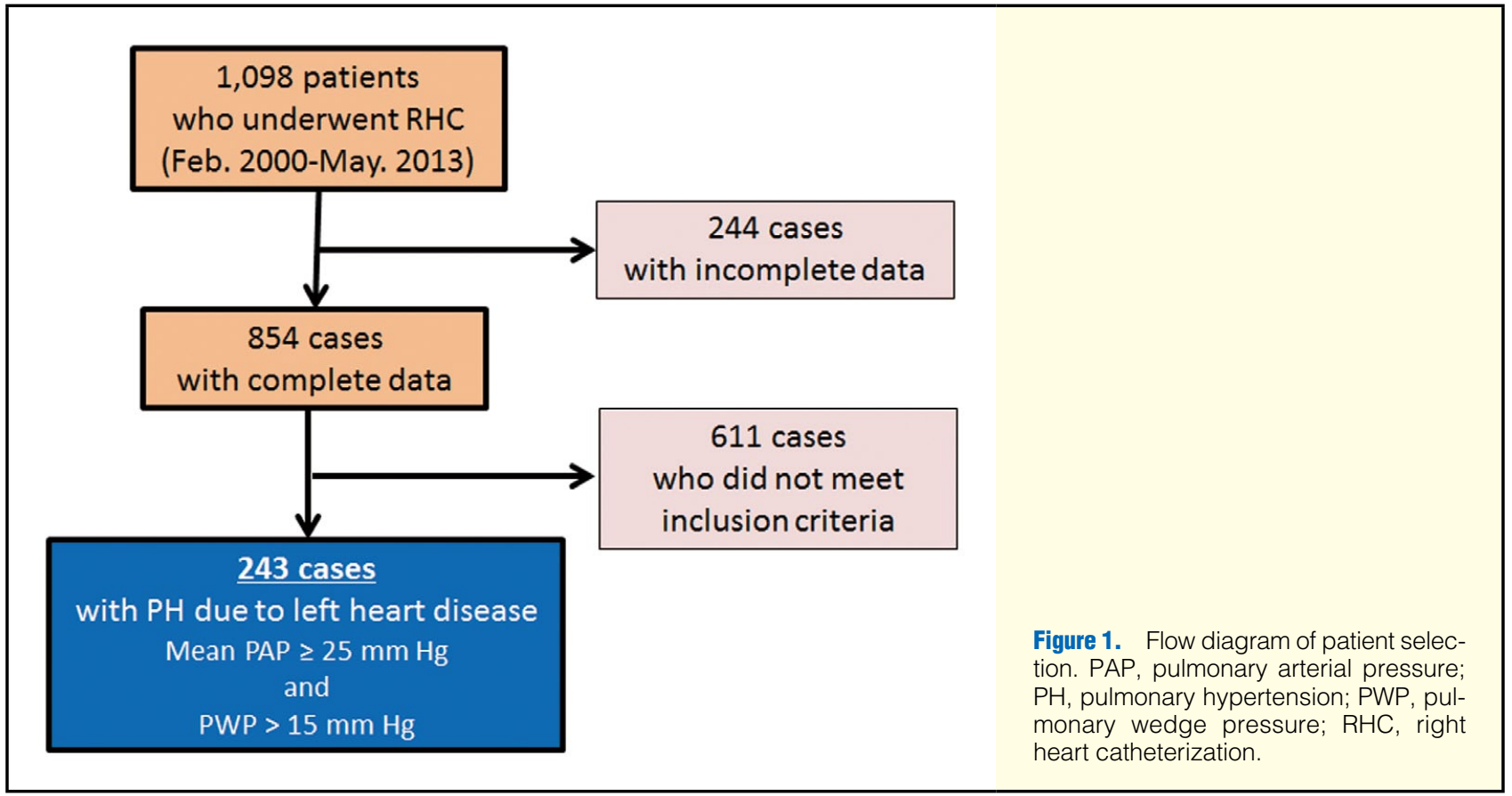

admission (range, 0-6th hospital day). TPG (defined as mean PAP-mean PWP), PVR (defined as TPG/cardiac output [CO]), and DPG (defined as diastolic PAP-mean PWP) were obtained by calculation. ${ }^{3}$ Moderate or severe valvular dysfunction were considered as potential etiologies. Left ventricular (LV) mass index was assessed using the M-mode method on echocardiography. Informed consent was obtained from each patient and this study was approved by the ethics committee at Hiroshima University.

\section{Statistical Analysis}

Continuous variables are shown as mean \pm SD for normally distributed variables and as median (IQR) for non-normally distributed variables. To compare difference between survivors and non-survivors, unpaired t-test or Mann-Whitney test was used as appropriate. Categorical variables are shown as numbers (percentages) and were compared using the chisquares test. The date of RHC was used as the enrolment date into the study. The endpoint was all-cause death. The data were censored in October 2014 or at the last time of visit for patients who were lost to follow-up $(n=19,7.8 \%)$. Survival was estimated using the Kaplan-Meier method and compared with the log-rank test. Cox proportional hazard regression analysis was performed to determine prognostic factors. Univariate analysis was performed with all baseline characteristic variables. Seven variables with $\mathrm{P}<0.05$ and mean RAP $(\mathrm{P}=0.059)$ remained candidates for multivariate analysis. On multivariate analysis, 3 efficient models were considered after cross-validation to minimize interaction between candidates. The fact that the number of data on New York Heart Association (NYHA) class and N-terminal pro-brain natriuretic peptide (NT-pro BNP) was small was also taken into consideration when selecting covariates in a model. The cut-off points for age, systolic blood pressure, NT-pro BNP, estimated glomerular filtration rate (eGFR), hemoglobin, RAP, PAP, PWP, and LV mass index were obtained using receiver operating characteristic curves. Other cut-off points were determined if they were clinically important or easy to interpret. All statistical analysis was performed using JMP10 (SAS Institute, Cary, $\mathrm{NC}$, USA), and results were considered statistically significant at $\mathrm{P}<0.05$.

\section{Results}

Mean patient age was $66 \pm 13$ years, and $87(34 \%)$ of the patients were women. Table 1 lists patient baseline characteristics. The average follow-up period was 52 months (range, 20-73 months) and 75 patients (31\%) died during follow-up. The causes of deaths are as follows: cardiac death, $\mathrm{n}=31$ $(48.4 \%)$; cancer, $n=6(9.4 \%)$; intracranial hemorrhage, $n=2$ $(3.1 \%)$; other causes, $n=9(14.1 \%)$; and unspecified, $n=16$ (25.0\%). The 1-, 3- and 5-year survival rates for all patients were $89 \%, 80 \%$ and $70 \%$, respectively. Admission for heart failure was higher in non-survivors. Kaplan-Meier survival estimates showed that only DPG among the hemodynamic measurements differentiated survivors from non-survivors, whereas other measurements including TPG and PVR did not (Figure 2). Elevated mean RAP showed a borderline significant association with mortality $(\mathrm{P}=0.058)$, although it significantly differentiated the survivors from non-survivors in the earlier phase (Figure 2). Elevated NT-pro BNP, decreased eGFR, anemia and the presence of coronary artery disease clearly differentiated survivors from non-survivors (Figure 3).

On univariate Cox proportional hazard regression analysis, 8 variables remained candidates for multivariate analysis (Table 2). On multivariate analysis, age, more severe NYHA class, elevated NT-pro BNP, decreased eGFR, and anemia were associated with mortality (Table 3 ). Among hemodynamic measurements, only DPG was associated with mortality, but it had lower prognostic ability.

\section{Discussion}

In the present study, we reviewed 243 patients with $\mathrm{PH}$ due to LHD, defined as mPAP $\geq 25 \mathrm{mmHg}$ and PWP $>15 \mathrm{mmHg}$, to identify prognostic factors. On multivariate analysis only DPG 


\begin{tabular}{|c|c|c|c|c|c|}
\hline Variables & $n^{\dagger}$ & All patients $(n=243)$ & Non-survivors $(n=75)$ & Survivors $(n=168)$ & P-value \\
\hline Age (years) & 243 & $66.1 \pm 13.2$ & $69.5 \pm 1.5$ & $64.6 \pm 1.0$ & $0.0063^{\prime}$ \\
\hline Female & 243 & $87(35.8)$ & $23(30.7)$ & $64(38.1)$ & 0.26 \\
\hline $\operatorname{BMI}\left(\mathrm{kg} / \mathrm{m}^{2}\right)$ & 242 & $23.2 \pm 3.8$ & $22.3 \pm 0.4$ & $23.6 \pm 0.3$ & $0.020^{*}$ \\
\hline NYHA III or IV & 139 & $91(65.5)$ & 30 (83.3) & $61(59.2)$ & 0.0063 \\
\hline Leg edema & 164 & $63(38.4)$ & $22(47.8)$ & $41(34.8)$ & 0.12 \\
\hline \multicolumn{6}{|l|}{ Etiology } \\
\hline CAD & 226 & $90(39.8)$ & $34(51.5)$ & $56(35.0)$ & $0.021^{*}$ \\
\hline Aortic stenosis & 200 & $25(12.5)$ & $7(12.7)$ & $18(12.4)$ & 0.95 \\
\hline Aortic regurgitation & 201 & $31(15.4)$ & $9(16.4)$ & $22(15.1)$ & 0.82 \\
\hline Mitral stenosis & 200 & $12(6.0)$ & $5(8.9)$ & $7(4.9)$ & 0.28 \\
\hline Mitral regurgitation & 207 & $105(50.7)$ & $28(48.3)$ & $77(51.7)$ & 0.66 \\
\hline Tricuspid regurgitation & 203 & $71(35.0)$ & $25(43.1)$ & $46(31.7)$ & 0.13 \\
\hline \multicolumn{6}{|l|}{ I.v. medications prior to $\mathrm{RHC}$} \\
\hline Carperitide & 204 & $18(8.8)$ & $7(11.7)$ & $11(7.6)$ & 0.36 \\
\hline Catecholamines & 204 & $24(11.8)$ & $8(13.3)$ & $16(11.1)$ & 0.65 \\
\hline \multicolumn{6}{|l|}{ Medications } \\
\hline Diuretics & 241 & $174(72.2)$ & $51(68.9)$ & $123(73.7)$ & 0.45 \\
\hline ACEI or ARB & 241 & $125(51.9)$ & $41(55.4)$ & $84(50.3)$ & 0.46 \\
\hline$\beta$-blocker & 241 & $112(46.5)$ & $28(37.8)$ & $84(50.3)$ & 0.072 \\
\hline Statin & 241 & $68(28.2)$ & $16(21.6)$ & $52(31.1)$ & 0.12 \\
\hline Amiodarone & 241 & $25(10.3)$ & $6(8.1)$ & $19(11.4)$ & 0.43 \\
\hline Spironolactone & 241 & $110(45.6)$ & $33(44.6)$ & $77(46.1)$ & 0.83 \\
\hline Inotropic agent & 241 & $17(7.1)$ & $6(8.1)$ & $11(6.6)$ & 0.67 \\
\hline \multicolumn{6}{|l|}{ Blood pressure $(\mathrm{mmHg})$} \\
\hline Systolic & 242 & $121.6 \pm 22.6$ & $121.8 \pm 2.6$ & $121.6 \pm 1.8$ & 0.94 \\
\hline Diastolic & 242 & $67.9 \pm 16.0$ & $70.1 \pm 1.8$ & $66.9 \pm 1.2$ & 0.16 \\
\hline \multicolumn{6}{|l|}{ Laboratory findings } \\
\hline NT-pro BNP (pg/ml) & 129 & $2,251(1,024-7,416)$ & $5,526(1,736-13,972)$ & $1,784(834-5,375)$ & $0.0079^{\prime}$ \\
\hline Creatinine (mg/dl) & 242 & $0.95(0.77-1.32)$ & $1.18(0.81-2.23)$ & $0.91(0.75-1.24)$ & $0.0035^{\prime}$ \\
\hline eGFR $\left(\mathrm{ml} / \mathrm{min} / 1.73 \mathrm{~m}^{2}\right)$ & 242 & $55.0(38.4-71.2)$ & $45.9(25.2-68.0)$ & $58.0(43.0-74.8)$ & 0.0039 \\
\hline $\mathrm{Hb}(\mathrm{g} / \mathrm{dl})$ & 241 & $12.1 \pm 2.4$ & $11.1 \pm 0.3$ & $12.6 \pm 0.2$ & $<0.001^{*}$ \\
\hline $\mathrm{HbA1c}(\%)$ & 220 & $6.0 \pm 1.0$ & $6.2 \pm 0.1$ & $6.0 \pm 0.1$ & 0.14 \\
\hline \multicolumn{6}{|l|}{ Hemodynamics } \\
\hline Heart rate (beats/min) & 242 & $77.2 \pm 18.2$ & $80.9 \pm 2.1$ & $75.5 \pm 1.4$ & $0.031^{*}$ \\
\hline Mean RAP (mmHg) & 243 & $11.7 \pm 6.0$ & $12.0 \pm 0.7$ & $11.5 \pm 0.5$ & 0.56 \\
\hline Systolic PAP (mmHg) & 243 & $46.8 \pm 12.9$ & $49.3 \pm 1.5$ & $45.7 \pm 1.0$ & $0.046^{*}$ \\
\hline Diastolic PAP (mmHg) & 243 & $24.6 \pm 7.2$ & $25.4 \pm 0.8$ & $24.2 \pm 0.6$ & 0.20 \\
\hline Mean PAP $(\mathrm{mmHg})$ & 243 & $34.1 \pm 8.5$ & $35.7 \pm 1.0$ & $33.4 \pm 0.7$ & $0.048^{*}$ \\
\hline PWP (mmHg) & 243 & $24.3 \pm 6.2$ & $24.6 \pm 0.7$ & $24.1 \pm 0.5$ & 0.56 \\
\hline $\mathrm{CO}(\mathrm{L} / \mathrm{min})$ & 243 & $4.4 \pm 1.5$ & $4.4 \pm 0.2$ & $4.3 \pm 0.1$ & 0.77 \\
\hline Cardiac index $\left(\mathrm{L} \cdot \mathrm{min}^{-1} \cdot \mathrm{m}^{-2}\right)$ & 243 & $2.7 \pm 0.9$ & $2.7 \pm 0.1$ & $2.7 \pm 0.1$ & 0.55 \\
\hline TPG $(\mathrm{mmHg})$ & 243 & $9(6-13)$ & $10(7-13)$ & $8.5(5-12)$ & 0.057 \\
\hline PVR (Wood units) & 243 & $2.0(1.3-3.2)$ & $2.3(1.5-3.4)$ & $1.9(1.3-3.0)$ & 0.063 \\
\hline $\mathrm{DPG}(\mathrm{mmHg})$ & 243 & 0 (-3 to 3$)$ & $1(-4$ to 4$)$ & $0(-3$ to 3$)$ & 0.37 \\
\hline \multicolumn{6}{|l|}{ Echocardiography } \\
\hline LVEF (\%) & 230 & $50.1 \pm 17.2$ & $46.7 \pm 2.1$ & $51.4 \pm 1.3$ & 0.053 \\
\hline LVDd $(\mathrm{cm})$ & 226 & $5.3 \pm 1.0$ & $5.3 \pm 0.1$ & $5.3 \pm 0.1$ & 0.58 \\
\hline LVDs $(\mathrm{cm})$ & 224 & $3.8(3.1-4.6)$ & $3.9(3.2-4.6)$ & $3.7(3.0-4.5)$ & 0.32 \\
\hline $\operatorname{LAD}(\mathrm{cm})$ & 225 & $4.5 \pm 0.9$ & $4.6 \pm 0.1$ & $4.5 \pm 0.1$ & 0.25 \\
\hline LV mass index $\left(\mathrm{g} / \mathrm{m}^{2}\right)$ & 222 & $125.3 \pm 46.0$ & $134.0 \pm 5.6$ & $122.4 \pm 3.6$ & 0.08 \\
\hline$E / A$ & 135 & $1.2(0.78-2.0)$ & $1.0(0.72-1.8)$ & $1.3(0.81-2.3)$ & 0.16 \\
\hline$E / e^{\prime}$ & 132 & $18.0(12.9-24.8)$ & $19.3(13.2-25.3)$ & $17.4(12.8-24.2)$ & 0.79 \\
\hline Admission for heart failure & 243 & $67(27.6)$ & $27(36.0)$ & $40(23.8)$ & $0.049^{*}$ \\
\hline
\end{tabular}

Data given as mean $\pm S D$, median (IQR) or $n(\%)$. ${ }^{*} P<0.05$. ${ }^{\dagger}$ No. patients available for analysis. $A C E I$, angiotensin-converting enzyme inhibitor; ARB, angiotensin II receptor blocker; BMI, body mass index; CAD, coronary artery disease; CO, cardiac output; DPG, diastolic pulmonary vascular pressure gradient; eGFR, estimated glomerular filtration rate; Hb, hemoglobin; LAD, left atrial dimension; LVDd, left ventricular diastolic dimension; LVDs, left ventricular systolic dimension; LVEF, left ventricular ejection fraction; NT-pro BNP, N-terminal pro-brain natriuretic peptide; NYHA, New York Heart Association; PAP, pulmonary arterial pressure; PVR, pulmonary vascular resistance; PWP, pulmonary wedge pressure; RAP, right atrial pressure; TPG, transpulmonary pressure gradient. 

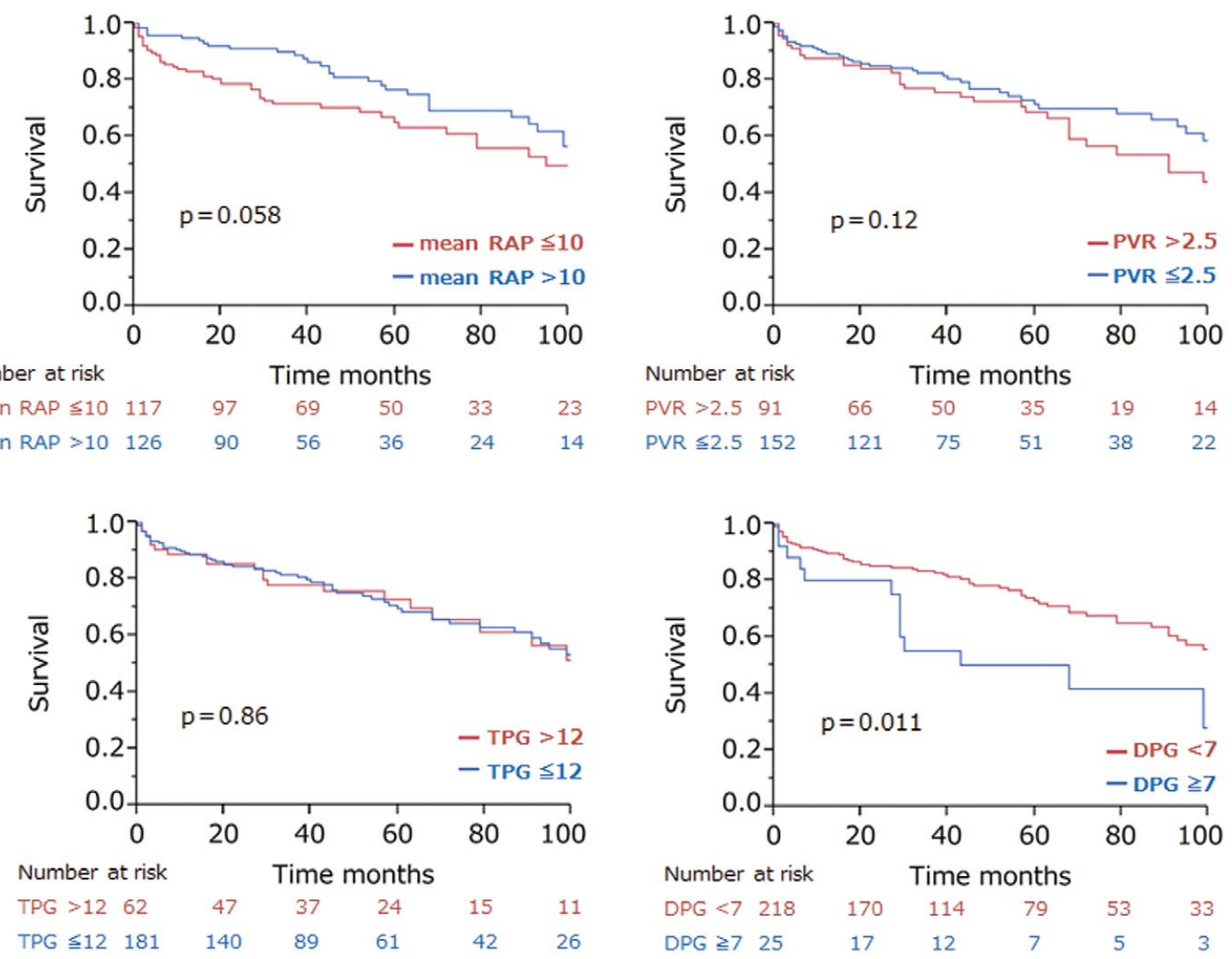

Figure 2. Kaplan-Meier survival estimates for hemodynamic measurements. Diastolic pulmonary vascular pressure gradient (DPG) $\geq 7 \mathrm{mmHg}$ discriminated survivors from non-survivors, whereas transpulmonary pressure gradient (TPG) $>12 \mathrm{mmHg}$, and pulmonary vascular resistance (PVR) $>2.5$ wood units did not. Mean right atrial pressure (RAP) $>10 \mathrm{mmHg}$ differentiated the survivors from non-survivors only in the earlier phase.

among the hemodynamic measurements had a weak prognostic ability. Mean RAP and current markers of pulmonary vascular remodeling such as TPG and PVR did not have a significant prognostic effect in this study. Clinical factors including NT-pro BNP, NYHA class, anemia, and renal dysfunction were superior in prognostication.

$\mathrm{PH}$ due to LHD is initiated by backward transmission of elevated LAP, and then followed by pulmonary vascular remodeling, so-called reactive $\mathrm{PH} .{ }^{2}$ Sustained $\mathrm{PH}$ causes right ventricular hypertrophy, which ultimately leads to irreversible right heart failure. The present study focused on the 2 conditions of right ventricular dysfunction and pulmonary vascular remodeling, and evaluated the prognostic abilities of the hemodynamic parameters that represent these conditions.

The RA appears to compensate for right ventricular dysfunction via distensibility, according to an experiment with dogs under treatment with chronic pulmonary artery banding. ${ }^{9}$ The RA maintains $\mathrm{CO}$ with a minimal rise ${ }^{9}$ or a decrease in RAP. ${ }^{10}$ In other words, elevated mean RAP can reflect decompensated right ventricular dysfunction. Previous studies in patients with pulmonary arterial hypertension have reported that mean RAP was associated with survival. ${ }^{11-16}$ Right ventricular function, mainly right ventricular ejection fraction (RVEF), evaluated on echocardiography and magnetic resonance imaging is closely related to survival in patients with
$\mathrm{PAH},{ }^{17-20}$ and similar findings on echocardiography, thermodilution catheterization, and radionuclide ventriculography have been reported in the setting of LHD. ${ }^{21-24}$ Using thermodilution-derived RVEF, Ghio et al clearly showed that the combination of $\mathrm{PH}$ and right ventricular dysfunction had a worse effect on survival in patients with chronic heart failure than in patients with either PH or right ventricular dysfunction. ${ }^{25}$ Thus, elevated mean RAP, partly caused by right ventricular dysfunction was expected to have a prognostic impact on survival in patients with PH due to LHD. In the present study, Kaplan-Meier analysis for elevated mean RAP showed a borderline significant association with mortality, but the multivariate analysis failed to confirm an independent prognostic ability. The previous studies reported the prognostic effect of central venous pressure ${ }^{26}$ and jugular venous pressure as ascertained on physical examination ${ }^{27}$ in patients with heart failure. The present study however, showed that the prognostic ability of mean RAP is poor in the setting of group $2 \mathrm{PH}$. With regard to right ventricular function, RAP has 2 major problems. First, the elevation in mean RAP was caused by PH, volume overload, tricuspid valvular disease, left-right shunt, right ventricular infarction, and cardiac tamponade other than right ventricular dysfunction. Second, right ventricular filling indices including mean RAP was markedly load dependent.

Recent studies have investigated the relationships between 

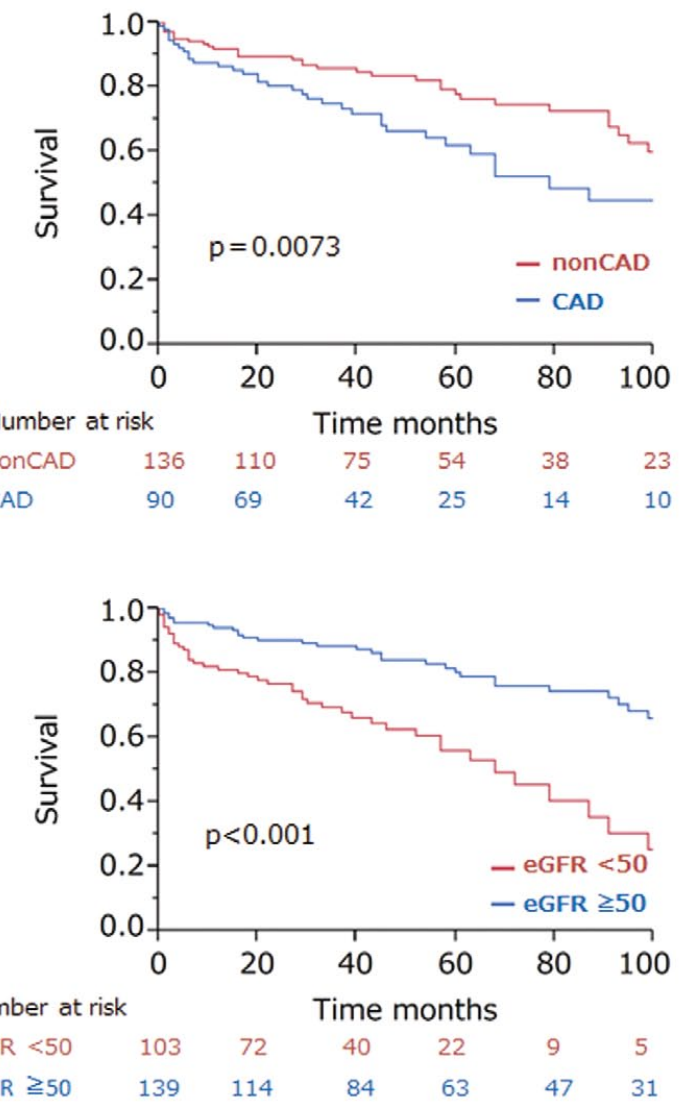

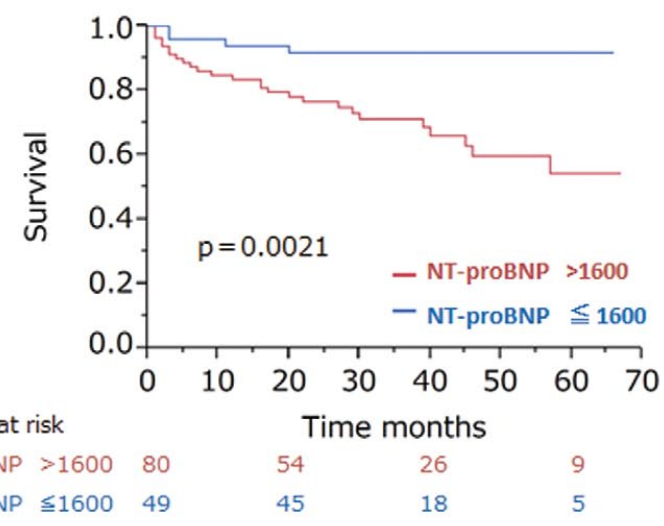

Number at risk

NT-proBNP $>1600 \quad 80$

NT-proBNP $\leqq 1600 \quad 49$

54

18

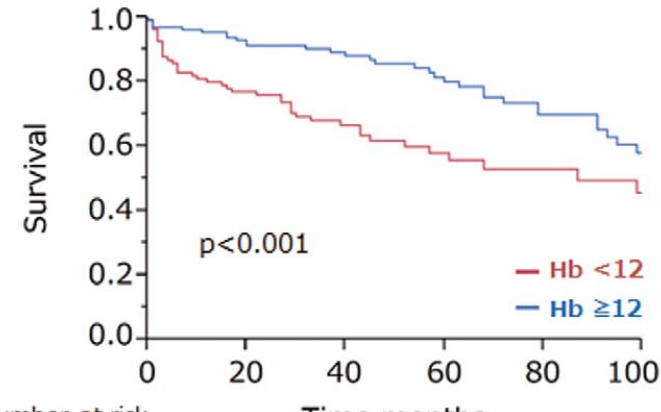

Number at risk Time months

$\begin{array}{llccccc}\mathrm{Hb}<12 & 108 & 76 & 44 & 27 & 16 & 13 \\ \mathrm{Hb} \geqq 12 & 133 & 109 & 79 & 57 & 40 & 22\end{array}$

Figure 3. Kaplan-Meier survival estimates for clinical variables. The presence of coronary artery disease (CAD), N-terminal probrain natriuretic peptide (NT-pro BNP) $>1,600 \mathrm{pg} / \mathrm{ml}$, estimated glomerular filtration rate (eGFR; $\left.<50 \mathrm{ml} / \mathrm{min} / 1.73 \mathrm{~m}^{2}\right)$, and hemoglobin $(\mathrm{Hb})<12 \mathrm{~g} / \mathrm{dl}$ discriminated survivors from non-survivors.

markers of pulmonary vascular remodeling and survival in patients with LHD, ${ }^{4-8}$ but the usefulness of such markers in prognostication is still controversial. TPG, which has been found to be associated with mortality, is used for the definition of reactive $\mathrm{PH}$ in the relevant guideline. ${ }^{3}$ Tatebe et al showed that PVR was associated with mortality, but their subjects included non-PH patients, and the presence of $\mathrm{PH}$ was not adjusted for in multivariate analysis. ${ }^{4}$ Hirashiki et al showed that there were no differences between reactive and passive $\mathrm{PH}$ in the incidence of cardiac events, although the sample size was small. ${ }^{5}$ The problem is that TPG and PVR are affected by cardiac output, ${ }^{28}$ whereas DPG is less sensitive to this effect. Gerges et al showed that DPG $\geq 7 \mathrm{mmHg}$ identified high-risk patients with reactive $\mathrm{PH}$ (PH due to LHD and TPG $>12 \mathrm{mmHg}$ ) on Kaplan-Meier analysis and that DPG was associated with more severe pulmonary vascular remodeling on histological analysis. ${ }^{6}$ In contrast, Tedford et al reported the poor prognostic ability of DPG in patients with PH due to LHD even though they used multiple cut-off points. ${ }^{7,8}$ Their subjects included younger patients ${ }^{7,8}$ and those with less coronary artery disease ${ }^{8}$ compared with the Gerges et al study. ${ }^{6}$ The problem is that DPG is sensitive to measurement error because the absolute value is small, and DPG is affected by many factors including lung disease, sepsis, hypoxia, acidosis, and coronary artery bypass surgery. ${ }^{7,8} \mathrm{We}$ conclude that DPG might have a weak prognostic ability, but the use of DPG in prognostication is limited in the setting of group $2 \mathrm{PH}$.

In addition, PWP does not predict mortality because PWP can paradoxically decrease owing to impaired LV filling in patients with severe PH due to LHD. ${ }^{29}$ In the present study the E/e' cut-off point of $13 \mathrm{mmHg}$ did not have a prognostic ability, possibly because most of the present patients $(75 \%)$ had E/e' $\geq 13$. The paradoxical decrease in PWP can also influence E/e' because E/e' reflects LAP or PWP. A recent study showed that underweight patients had worse prognosis for advanced heart failure than overweight patients. ${ }^{30}$ In the present study, there was a tendency for poor prognosis in patients with lower BMI, but BMI did not remain a candidate for multivariate analysis. Reduced eGFR and anemia are well-known to be associated with increased mortality in heart failure. ${ }^{31-33}$ Similarly, we showed that renal dysfunction and anemia are potent prognostic factors in patients with PH due to LHD.

\section{Study Limitations}

This was a retrospective, single-center study that targeted a heterogeneous population involving different etiologies of heart failure. Although physical findings including jugular vein distension and heart sounds can have prognostic impact in patients with PH due to LHD, sufficient data for analysis were not obtained. Data on right ventricular function were unavailable. 


\begin{tabular}{|c|c|c|c|}
\hline \multirow{2}{*}{ Variables } & \multicolumn{3}{|c|}{ Univariate } \\
\hline & HR & $95 \% \mathrm{Cl}$ & P-value \\
\hline Age $\geq 60$ years & 1.79 & $1.03-3.33$ & $0.038^{*}$ \\
\hline Female & 0.92 & $0.71-1.20$ & 0.55 \\
\hline $\mathrm{BMI}<18.5 \mathrm{~kg} / \mathrm{m}^{2}$ & 1.60 & $0.66-3.29$ & 0.27 \\
\hline BMI $18.5-25 \mathrm{~kg} / \mathrm{m}^{2}$ & 1.00 & & \\
\hline $\mathrm{BMI} \geq 25 \mathrm{~kg} / \mathrm{m}^{2}$ & 0.68 & $0.38-1.17$ & 0.17 \\
\hline NYHA III or IV & 3.05 & $1.36-8.13$ & $0.0054^{*}$ \\
\hline NYHA I or II & 1.00 & & \\
\hline Leg edema & 1.64 & $0.91-2.93$ & 0.098 \\
\hline CAD & 1.92 & $1.18-3.12$ & $0.0089^{*}$ \\
\hline Tricuspid regurgitation & 1.66 & $0.98-2.79$ & 0.060 \\
\hline$\beta$-blocker & 0.72 & $0.44-1.14$ & 0.16 \\
\hline Statin & 0.73 & $0.40-1.24$ & 0.25 \\
\hline $\mathrm{SBP}>140 \mathrm{mmHg}$ & 1.21 & $0.69-2.01$ & 0.50 \\
\hline NT-pro BNP $>1,600 \mathrm{pg} / \mathrm{ml}$ & 4.51 & $1.75-15.3$ & $<0.001^{*}$ \\
\hline eGFR $<50 \mathrm{ml} / \mathrm{min} / 1.73 \mathrm{~m}^{2}$ & 3.08 & $1.92-5.01$ & $<0.001^{*}$ \\
\hline $\mathrm{Hb}<12 \mathrm{~g} / \mathrm{dl}$ & 2.34 & $1.48-3.76$ & $<0.001^{*}$ \\
\hline $\mathrm{HbA} 1 \mathrm{c} \geq 7.0 \%$ & 1.53 & $0.81-2.68$ & 0.18 \\
\hline \multicolumn{4}{|l|}{ Hemodynamics } \\
\hline Heart rate $>100$ beats $/ \mathrm{min}$ & 1.98 & $0.95-3.69$ & 0.065 \\
\hline Mean RAP $>10 \mathrm{mmHg}$ & 1.55 & $0.98-2.47$ & 0.059 \\
\hline Systolic PAP >60 mmHg & 1.51 & $0.84-2.56$ & 0.16 \\
\hline Diastolic PAP $>30 \mathrm{mmHg}$ & 1.69 & $0.95-2.84$ & 0.071 \\
\hline Mean PAP >50 mmHg & 1.41 & $0.59-2.85$ & 0.41 \\
\hline $\mathrm{PWP}>30 \mathrm{mmHg}$ & 1.17 & $0.65-1.98$ & 0.59 \\
\hline $\mathrm{CO}<4.0 \mathrm{~L} / \mathrm{min}$ & 1.21 & $0.77-1.92$ & 0.41 \\
\hline Cardiac index $<2.5 \mathrm{~L} \cdot \mathrm{min}^{-1} \cdot \mathrm{m}^{-2}$ & 1.26 & $0.80-1.98$ & 0.32 \\
\hline $\mathrm{TPG}>12 \mathrm{mmHg}$ & 1.05 & $0.62-1.71$ & 0.86 \\
\hline PVR $>2.5$ wood units & 1.36 & $0.86-2.14$ & 0.19 \\
\hline $\mathrm{DPG} \geq 7 \mathrm{mmHg}$ & 2.12 & $1.11-3.74$ & $0.024^{*}$ \\
\hline \multicolumn{4}{|l|}{ Echocardiography } \\
\hline LVEF $<50 \%$ & 1.41 & $0.88-2.27$ & 0.15 \\
\hline LVDd $>5.5 \mathrm{~cm}$ & 0.91 & $0.54-1.49$ & 0.71 \\
\hline LVDs $>4.0 \mathrm{~cm}$ & 1.14 & $0.70-1.85$ & 0.60 \\
\hline$L A D>4.0 \mathrm{~cm}$ & 1.29 & $0.76-2.30$ & 0.36 \\
\hline LV mass index $>130 \mathrm{~g} / \mathrm{m}^{2}$ & 1.08 & $0.66-1.76$ & 0.75 \\
\hline$E / A>2.0$ & 0.49 & $0.17-1.15$ & 0.10 \\
\hline$E / e^{\prime} \geq 13$ & 1.12 & $0.51-2.80$ & 0.80 \\
\hline Admission for heart failure & 1.40 & $0.86-2.23$ & 0.17 \\
\hline
\end{tabular}

${ }^{*} \mathrm{P}<0.05$. SBP, systolic blood pressure. Other abbreviations as in Table 1.

\begin{tabular}{|c|c|c|c|c|c|c|c|c|c|}
\hline \multirow[t]{2}{*}{ Variables } & \multicolumn{3}{|c|}{ Regression 1} & \multicolumn{3}{|c|}{ Regression 2} & \multicolumn{3}{|c|}{ Regression 3} \\
\hline & HR & $95 \% \mathrm{Cl}$ & P-value & HR & $95 \% \mathrm{Cl}$ & P-value & HR & $95 \% \mathrm{Cl}$ & P-value \\
\hline Age $>60$ years & 2.80 & $1.03-9.81$ & $0.042^{*}$ & 1.98 & $1.03-9.81$ & $0.029^{*}$ & 2.06 & $1.11-4.18$ & $0.020^{*}$ \\
\hline NYHA III or IV & 3.19 & $1.22-9.92$ & $0.017^{*}$ & & & & & & \\
\hline CAD & 2.04 & $0.89-4.99$ & 0.093 & 1.57 & $0.95-2.59$ & 0.077 & 1.70 & $1.04-2.79$ & $0.034^{*}$ \\
\hline NT-pro BNP $>1,600 \mathrm{pg} / \mathrm{ml}$ & 4.04 & $1.22-18.4$ & $0.021^{*}$ & & & & & & \\
\hline eGFR $<50 \mathrm{ml} / \mathrm{min} / 1.73 \mathrm{~m}^{2}$ & 0.98 & $0.40-2.44$ & 0.96 & 1.78 & $1.03-3.12$ & $0.040^{*}$ & & & \\
\hline $\mathrm{Hb}<12 \mathrm{~g} / \mathrm{dl}$ & 1.44 & $0.60-3.70$ & 0.42 & 1.81 & $1.06-3.13$ & $0.029^{*}$ & 2.23 & $1.36-3.72$ & $0.034^{*}$ \\
\hline Mean RAP $>10 \mathrm{mmHg}$ & 0.84 & $0.32-2.11$ & 0.70 & 1.31 & $0.80-2.16$ & 0.29 & 1.29 & $0.79-2.15$ & 0.31 \\
\hline $\mathrm{DPG} \geq 7 \mathrm{mmHg}$ & 1.33 & $0.40-3.89$ & 0.62 & 1.81 & $0.93-3.29$ & 0.079 & 2.07 & $1.07-3.72$ & $0.031^{*}$ \\
\hline
\end{tabular}

${ }^{*} \mathrm{P}<0.05$. Abbreviations as in Table 1. 


\section{Conclusions}

This retrospective study of 243 patients with PH due to LHD evaluated the prognostic ability of mean RAP and markers of pulmonary vascular remodeling such as TPG, PVR, and DPG. Conclusively, the use of these hemodynamic parameters in prognostication is limited. Clinical factors including NT-pro BNP, NYHA class, renal dysfunction, and anemia are superior in prognostication in these patients.

\section{Acknowledgments}

The authors gratefully thank the staff of Hiroshima University Hospital for contributing to this study.

\section{Disclosures}

This work was not supported by grants.

\section{References}

1. Guazzi M, Borlaug BA. Pulmonary hypertension due to left heart disease. Circulation 2012; 126: 975-990.

2. Guglin M, Khan H. Pulmonary hypertension in heart failure. J Card Fail 2010; 16: 461-474

3. Galiè N, Hoeper MM, Humbert M, Torbicki A, Vachiery JL, Barbera JA, et al; ESC Committee for Practice Guidelines (CPG). Guidelines for the diagnosis and treatment of pulmonary hypertension: The Task Force for the Diagnosis and Treatment of Pulmonary Hypertension of the European Society of Cardiology (ESC) and the European Respiratory Society (ERS), endorsed by the International Society of Heart and Lung Transplantation (ISHLT). Eur Heart J 2009; 30: $2493-2537$.

4. Tatebe S, Fukumoto Y, Sugimura K, Miyamichi-Yamamoto S, Aoki $\mathrm{T}$, Miura $\mathrm{Y}$, et al. Clinical significance of reactive post-capillary pulmonary hypertension in patients with left heart disease. Circ J 2012; 76: $1235-1244$.

5. Hirashiki A, Kondo T, Adachi S, Nakano Y, Shimazu S, Shimizu S, et al. Prognostic value of pulmonary hypertension in ambulatory patients with non-ischemic dilated cardiomyopathy. Circ J 2014; 78: $1245-1253$.

6. Gerges C, Gerges M, Lang MB, Zhang Y, Jakowitsch J, Probst P, et al. Diastolic pulmonary vascular pressure gradient: A predictor of prognosis in "out-of-proportion" pulmonary hypertension. Chest 2013; 143: 758-766.

7. Tedford RJ, Beaty CA, Mathai SC, Kolb TM, Damico R, Hassoun $\mathrm{PM}$, et al. Prognostic value of the pre-transplant diastolic pulmonary artery pressure-to-pulmonary capillary wedge pressure gradient in cardiac transplant recipients with pulmonary hypertension. J Heart Lung Transplant 2014; 33: 289-297.

8. Tampakakis E, Leary PJ, Selby VN, De Marco T, Cappola TP, Felker GM, et al. The diastolic pulmonary gradient does not predict survival in patients with pulmonary hypertension due to left heart disease. JACC Heart Fail 2015; 3: 9-16.

9. Gaynor SL, Maniar HS, Bloch JB, Steendijk P, Moon MR. Right atrial and ventricular adaptation to chronic right ventricular pressure overload. Circulation 2005; 112: 212-218.

10. Suga $\mathrm{H}$. Importance of atrial compliance in cardiac performance. Circ Res 1974; 35: 39-43.

11. D'Alonzo GE, Barst RJ, Ayres SM, Bergofsky EH, Brundage BH, Detre KM, et al. Survival in patients with primary pulmonary hypertension: Results from a national prospective registry. Ann Intern Med 1991; 115: 343-349.

12. Thenappan T, Shah SJ, Rich S, Tian L, Archer SL, GombergMaitland M. Survival in pulmonary arterial hypertension: A reappraisal of the NIH risk stratification equation. Eur Respir J 2010; 35: 1079-1087.

13. Benza RL, Miller DP, Gomberg-Maitland M, Frantz RP, Foreman AJ, Coffey CS, et al. Predicting survival in pulmonary arterial hypertension: Insights from the Registry to Evaluate Early and Long-Term Pulmonary Arterial Hypertension Disease Management (REVEAL). Circulation 2010; 122: 164-172.

14. Thenappan T, Glassner C, Gomberg-Maitland M. Validation of the pulmonary hypertension connection equation for survival prediction in pulmonary arterial hypertension. Chest 2012; 141: 642-650.

15. Sandoval J, Bauerle O, Palomar A, Gómez A, Martínez-Guerra ML, Beltrán MS, et al. Survival in primary pulmonary hypertension: Validation of a prognostic equation. Circulation 1994; 89: $1733-$ 1744.

16. Adachi S, Hirashiki A, Nakano Y, Shimazu S, Murohara T, Kondo T. Prognostic factors in pulmonary arterial hypertension with Dana Point group 1. Life Sci 2014; 118: 404-409.

17. Vonk-Noordegraaf A, Haddad F, Chin KM, Forfia PR, Kawut SM, Lumens J, et al. Right heart adaptation to pulmonary arterial hypertension: Physiology and pathobiology. J Am Coll Cardiol 2013; 62: $22-33$.

18. Ghio S, Klersy C, Magrini G, D'Armini AM, Scelsi L, Raineri C, et al. Prognostic relevance of the echocardiographic assessment of right ventricular function in patients with idiopathic pulmonary arterial hypertension. Int J Cardiol 2010; 140: 272-278.

19. Schuuring MJ, van Riel AC, Vis JC, Duffels MG, van Dijk AP, de Bruin-Bon RH, et al. New predictors of mortality in adults with congenital heart disease and pulmonary hypertension: Midterm outcome of a prospective study. Int J Cardiol 2015; 181: 270-276.

20. Motoji Y, Tanaka H, Fukuda Y, Ryo K, Emoto N, Kawai H, et al. Efficacy of right ventricular free-wall longitudinal speckle-tracking strain for predicting long-term outcome in patients with pulmonary hypertension. Circ J 2013; 77: 756-763.

21. Haddad F, Doyle R, Murphy DJ, Hunt SA. Right ventricular function in cardiovascular disease, part II: Pathophysiology, clinical importance, and management of right ventricular failure. Circulation 2008; 117: $1717-1731$.

22. Meyer P, Filippatos GS, Ahmed MI, Iskandrian AE, Bittner V, Perry GJ, et al. Effects of right ventricular ejection fraction on outcomes in chronic systolic heart failure. Circulation 2010; 121: 252-258.

23. Desai RV, Guichard JL, Mujib M, Ahmed MI, Feller MA, Fonarow $\mathrm{GC}$, et al. Reduced right ventricular ejection fraction and increased mortality in chronic systolic heart failure patients receiving $\beta$-blockers: Insights from the BEST trial. Int J Cardiol 2013; 163: 61-67.

24. Meyer P, Desai RV, Mujib M, Feller MA, Adamopoulos C, Banach $\mathrm{M}$, et al. Right ventricular ejection fraction $<20 \%$ is an independent predictor of mortality but not of hospitalization in older systolic heart failure patients. Int J Cardiol 2012; 155: 120-125.

25. Ghio S, Gavazzi A, Campana C, Inserra C, Klersy C, Sebastiani R, et al. Independent and additive prognostic value of right ventricular systolic function and pulmonary artery pressure in patients with chronic heart failure. J Am Coll Cardiol 2001; 37: 183-188.

26. Damman K, van Deursen VM, Navis G, Voors AA, van Veldhuisen DJ, Hillege HL. Increased central venous pressure is associated with impaired renal function and mortality in a broad spectrum of patients with cardiovascular disease. J Am Coll Cardiol 2009; 53: 582-588.

27. Drazner MH, Rame JE, Stevenson LW, Dries DL. Prognostic importance of elevated jugular venous pressure and a third heart sound in patients with heart failure. $N$ Engl J Med 2001; 345: 574-581.

28. Naeije R, Vachiery JL, Yerly P, Vanderpool R. The transpulmonary pressure gradient for the diagnosis of pulmonary vascular disease. Eur Respir J 2013; 41: 217-223.

29. Butler J, Chomsky DB, Wilson JR. Pulmonary hypertension and exercise intolerance in patients with heart failure. J Am Coll Cardiol 1999; 34: 1802-1806.

30. Cai C, Hua W, Ding LG, Wang J, Chen KP, Yang XW, et al. Association of body mass index with cardiac reverse remodeling and long-term outcome in advanced heart failure patients with cardiac resynchronization therapy. Circ J 2014; 78: 2899-2907.

31. Smith GL, Lichtman JH, Bracken MB, Shlipak MG, Phillips CO, DiCapua P, et al. Renal impairment and outcomes in heart failure: Systematic review and meta-analysis. J Am Coll Cardiol 2006; 47: $1987-1996$

32. Horwich TB, Fonarow GC, Hamilton MA, MacLellan WR, Borenstein J. Anemia is associated with worse symptoms, greater impairment in functional capacity and a significant increase in mortality in patients with advanced heart failure. $J$ Am Coll Cardiol 2002; 39: 1780-1786.

33. Yamauchi T, Sakata Y, Takada T, Nochioka K, Miura M, Tadaki S, et al; CHART-2 investigators. Prognostic impact of anemia in patients with chronic heart failure: With special reference to clinical background: report from the CHART-2 Study. Circ J 2015; 79: 1984-1993. 